\title{
Long non-coding RNA MEG3 suppresses migration and invasion of thyroid carcinoma by targeting of Racl
}

\author{
C. H. WANG ${ }^{1}$, G. YAN ${ }^{2}$, Y. Q. ZHANG ${ }^{1}$, X. Q. JIA ${ }^{1}$, P. BU 3 ,*
}

${ }^{1}$ Department of pathology, Medical College of Yangzhou University, Jiangsu Co-innovation Center for Prevention and Control of Important Animal Infectious Diseases and Zoonoses, Yangzhou, 225009, China; ${ }^{2}$ Geriatric Ward, Jiangsu Huaian Hospital, Huaian, 223001, China; ${ }^{3}$ Jiangsu Key Laboratory of Integrated Traditional Chinese and Western Medicine for Prevention and Treatment of Senile Diseases, Medical College of Yangzhou University, Yangzhou, 225001, China

*Correspondence: wchai2000cn@aliyun.com

Received August 13, 2014 / Accepted January 4, 2015

\begin{abstract}
Thyroid cancer, the most common primary endocrine malignancy in adult, imperatively requires new therapeutic studies that could target the molecular regulatory mechanism. Even though emerging evidence showed that long noncoding RNAs (Lnc-RNAs) are involved in different biological characteristic of malignant tumor, such as cell growth and apoptosis as well as cancer progression and metastasis. Limited data are available on the function of Lnc-RNAs in thyroid cancer invasion and metastasis. Among the 5 tested lnc-RNAs, the present study demonstrates that MEG3 was significantly down-regulated in papillary thyroid carcinoma (PTC) tissues with lymph-node metastasis than in primary thyroid cancer. Moreover, the down- regulated MEG3 was associated with lymph-node metastasis. Over-expression of MEG3 could strongly inhibit the cell migration and invasion in TPC-1 and HTH83 thyroid cancer cell lines. In addition, we also showed that Rac1 was negatively regulated by lncRNA-MEG3 at the posttranscriptional level, via a specific target site within the 3 'UTR by dual luciferase reporter assay. The expression of Rac1 was inversely correlated with lncRNA-MEG3 expression in PTC tissues. Thus, this study suggests that MEG3 acts as novel suppressor of migration and invasion by targeting Rac1 gene.
\end{abstract}

Key words: MEG3, long noncoding RNA, RAC1, thyroid cancer, metastasis

Thyroid cancer is the most common primary endocrine neoplasm in adult. The estimated worldwide incidence rate is approximately $1.7 \%$ of total cancer diagnoses (1), and has increased in the recent decades. Mortality has been stable over the years with a rate of 0.368 per 100,000 people in China (2). There are four types of thyroid cancer: Papillary, Follicular, Medullary, and Anaplastic. Papillary cancer is the most common type, accounting for approximately $80-90 \%$ of all cases, and it is very treatable, and in many cases, curable. Papillary thyroid tumor often spreads to the cervical lymph nodes (3), and this metastasis is the major cause of fatal outcome. Therefore, it is essential to identify metastasis-associated molecules and to better understand the mechanisms behind the metastasis of thyroid carcinoma.

It is well known that RNAs include about 3\% coding RNAs and about $97 \%$ non-coding RNAs in human genome. LncRNAs are more than 200 bps nucleotide non-coding RNAs, it is not necessarily conserved among different species. Emerging evi- dence demonstrates that lnc-RNAs serve as oncogenes or tumor suppressor genes in development of tumor (4-7). However, the regulation of most lnc-RNAs and their precise mechanisms of action are not known in thyroid carcinoma.

Maternally expressed gene 3 (MEG3) is a lnc-RNA gene, located on chromosome 14q32 (8). In humans, MEG3 is expressed in many normal tissues. The loss of MEG3 expression has been found in various types of human tumors, including stomach, tongue, prostate, lung, bladder and menings, and it effected on tumor cellular proliferation, migration and invasion (9-15). However, little is known about the expression level and biological role of MEG3 in papillary thyroid carcinoma.

In this study, we detected the differential expression of 5 tested lnc-RNAs in human PTC samples using qRT-PCR, and investigated the function of MEG3 in migration and invasion of thyroid cancer cells. Moreover, we identified Racl as a target gene of MEG3 which regulates the invasion and migration of thyroid cancer cells. MEG3 might act as a tumor suppressor 
and serve as a potential therapeutic target in thyroid carcinoma.

\section{Materials and methods}

PTC tissues collection. A total of 16 cases tissue specimens from PTC were obtained from 16 PTC patients (age range, 40-62 years; nine males and seven females) at the Departments of Surgery of the Jiangsu Subai and Yangzhou Chinese Medical Hospitals affiliated to Yangzhou University (Yangzhou, China). 11 of 16 tissue specimens with lymph node metastases and 5 without metastases were confirmed by a pathologist. All tissues were obtained during surgery and immediately stored in liquid nitrogen prior to use. Approval for this study was granted by the Institute Research Medical Ethics Committee of the Medical College of Yangzhou University (Yangzhou, China). Patients provided written informed consent.

Cell line culture. TPC- 1 cells and HTH83 cells were kindly provided by Sissy Jhiang (The Ohio State University) and Dr N-E Heldin (University Hospital, Uppsala, Sweden),respectively. TPC-1, HTH83, and 293T cells (Fengshou, Shanghai, China) were cultured in Dulbecco modified Eagle medium (DMEM) containing 10\% fetal bovine serum (FBS) (HyClone Victoria, AUS), $100 \mathrm{IU} / \mathrm{ml}$ penicillin, and $100 \mathrm{mg} / \mathrm{ml}$ streptomycin, at $37^{\circ} \mathrm{C}$ in a humidified atmosphere containing $5 \% \mathrm{CO} 2$.

qRT-PCR detection and quantification. Total RNAs were isolated from cells by Trizol reagent(invitrogen, San Diego, USA), and reverse transcriptions were performed by Takara PrimeScript TM 1st Strand cDNA Synthesis kit (Takara, Dalian, JPN) following the manufacturer's instructions. qRT-PCR was performed using All-in-One qRT-PCR Detection Kit (GeneCopoeia, Rockville, MD) on an Applied Biosystems 7500 Real-Time PCR system (Applied Biosystems, White Plains, NY, USA). The U6 small RNA and $\beta$-actin mRNA were used as internal controls. All reactions were run in triplicate. Primers used for amplification are provided in Table I (16). All amplified products were verified through agarose gel electrophoresis. The $2{ }^{\Delta \Delta} \mathrm{Ct}$ method was used to calculate the

Table 1. Primer sequences for measurement of expression

\begin{tabular}{l}
\hline MEG3 Forward - 5'-GCCAAGCTTCTTGAAAGGCC-3' \\
Reverse - 5'-TTCCACGGAGTAGAGCGAGTC-3' \\
\hline HULC Forward - 5'-TCATGATGGAATTGGAGCCTT-3' \\
Reverse - 5'-CTCTTCCTGGCTTGCAGATTG-3' \\
\hline HOTAIR Forward - 5'-CAGTGGGGAACTCTGACTCG-3' \\
Reverse - 5'-GTGCCTGGTGCTCTCTTACC-3' \\
\hline NEAT1 Forward - 5'-TGGCTAGCTCAGGGCTTCAG-3' \\
Reverse - 5'-TCTCCTTGCCAAGCTTCCTTC-3' \\
\hline MALAT-1 Forward - 5'-TAGGAAGACAGCAGCAGACAGG-3' \\
Reverse - 5'-TTGCTCGCTTGCTCCTCAGT-3' \\
\hline U6 Forward -5'-CGCTTCGGCAGCACATATAC-3' \\
Reverse 5'-T TCACGAATTTGCGTGTC AT-3' \\
\hline
\end{tabular}

relative expression of each $\operatorname{lncRNA}$. The primers for RAC1 was 5'-AGGAAGGCGGACATATTAGTCCCT-3' and 5'-AGACG ATAGTTGGGTC CCGGC-3'.

Production of retroviral particles and infection of thyroid cancer cells. Rac-1 shRNA was purchased from Santa Cruz Biotechnology (Santa Cruz, USA). MEG3-MSCV plasmid and pRac-1-shRNA-MSCV were chemically synthesized at the Department of Pathology, Medical College of Yangzhou University (Yangzhou, Jiangshu) and sequenced by Sangon Biotech (Shanghai) Co., Ltd. (Shanghai, China). 293T cells were seeded on $90-\mathrm{mm}$ dishes 1 day before transfection. Then, $10 \mu \mathrm{g}$ retroviral plasmids together with $15 \mu \mathrm{g}$ MEG3-MSCV vector was used to cotransfect $293 \mathrm{~T}$ cells by the Lipofectamine 2000 (Invitrogen, San Diego, CA) according to the manufacturer's protocol. The retroviral supernatants were collected 48 hours after transfection and stored at $-80^{\circ} \mathrm{C}$. Next, $5-8 \mathrm{ml}$ supernatants containing MEG3-MSCV virus together with $8 \mu \mathrm{g} / \mathrm{mL}$ polybrene (Sigma, NY, USA) were used to infect TPC-1 and HTH83 cells. For infection of thyroid cancer cells, the cells were incubated at $37^{\circ} \mathrm{C}$ with $5 \% \mathrm{CO}_{2}$ (17).

TPC-1 and HTH83 Cells were also infected with shRac1MSCV virus or control MSCV empty vector as negative control (NC). The MEG3 and Rac1RNA level in the infected thyroid cancer cells were identified by qRT-PCR.

Dual luciferase reporter assay. The full length 3 '-UTR of Rac1 was amplified by PCR from genomic DNA and cloned into the EcoRI and XhaI sites of pGL3-BS vector (Promega, WI, USA). The primers for Rac1 3'-UTR were as follows: 5'- GTGAATTCTTGAACAGAACTG - $3{ }^{\prime}$ and $5{ }^{\prime}$ - GTTCTAGAACGAGTCAGTCTT - ${ }^{\prime}$. The mutant construct of Rac1 3'UTR was generated using a Quick Change mutagenesis kit (Stratagene, Heidelberg, Germany). Co-transfection of reporter vectors and MEG3-MSCV or negative control was performed using Lipofectamine 2000 (Invitrogen, San Diego, USA). After $48 \mathrm{~h}$, dual luciferase activity was measured using a dual luciferase reporter assay system according to the manufacturer's protocol (Promega, WI, USA).

Migration and invasion assay. In vitro cell transwell migration assays and transwell invasion assays were performed by using transwell chambers. For the migration assays, $5 \times 10^{4}$ cells were added into the upper chamber of 8 micron transwells (BD Bioscience, New Jersey, USA). For the invasion assays, $1 \times 10^{5}$ cells were added into the upper chamber of 8 micron transwells precoated with matrigel (BD Bioscience, New Jersey, USA). In both assays, cells were plated in medium without serum, and medium containing $10 \%$ FBS in the lower chamber served as chemoattractant. After $14 \mathrm{~h}$ incubation, the cells that did not migrate or invade through the pores were carefully cleared away. Then the filters were fixed in $90 \%$ alcohol and followed by crystal violet stain. Five random fields were counted per chamber by using an inverted microscope (CKX41; Olympus, Japan), and each test was repeated thrice.

Western blot analysis. Proteins were extracted by Cell lysis for western kit (Beyotime, Jiangsu, China) according to the instructions. Protein concentration was quantified using 


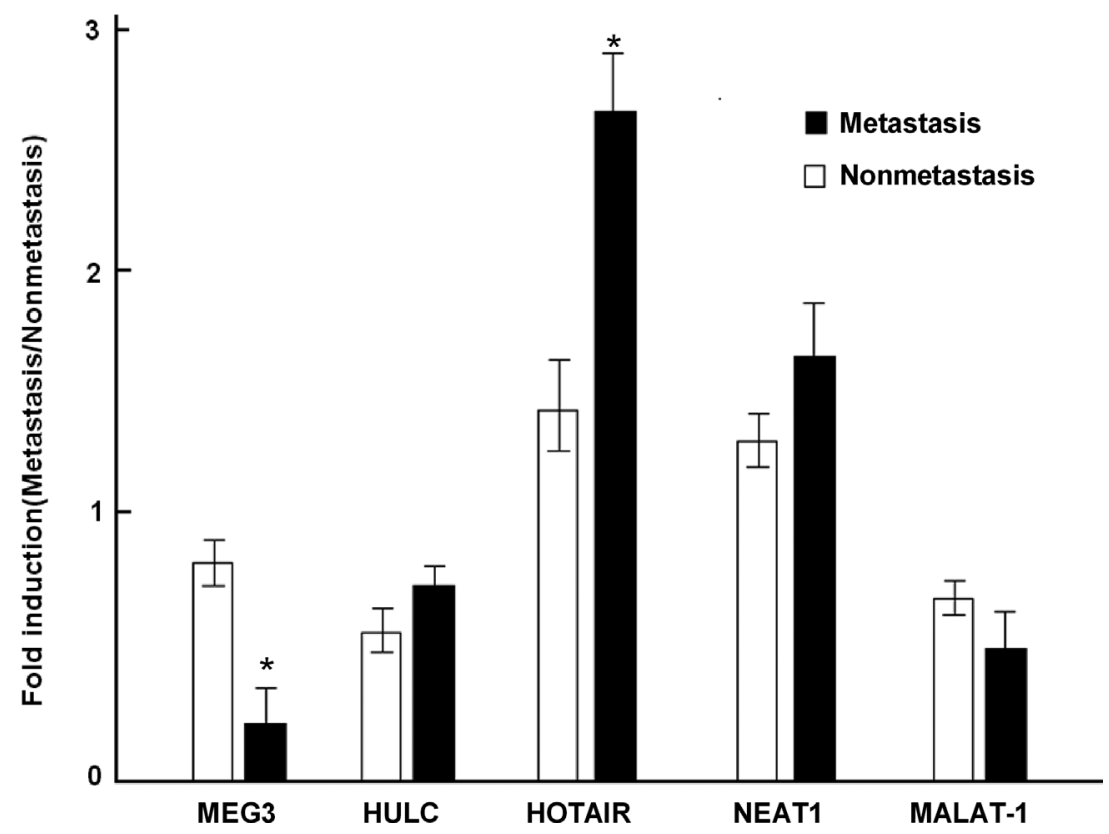

Figure 1. Five lnc-RNAs is expressed in papillary thyroid carcinoma as MEG3 is lost.

The five lnc-RNAs relative expression levels were determined by qRT-PCR in primary thyroid cancer and matched lymph node metastatic tissues and normalized against an endogenous U6 RNA control. The relative expression levels of MEG3 is down regulated in lymph node metastasis of thyroid cancer $(n=11)$ than in non-metastasis of primary thyroid carcinoma $(n=5)$. Student's $t$ test was used to analyze the significant differences, ${ }^{*} p<0.05$.

Enhanced BCA protein assay kit (Beyotime, Jiangsu, China). For western blot analysis, equal amounts of total protein were boiled, and separated by SDS-PAGE. After electrophoresis, protein was blotted onto a PVDF membrane and blocked for $2 \mathrm{~h}$ at room temperature.

Membranes were incubated with human monoclonal anti-rabbit Rac1 antibody (Cell Signaling Technologies, Boston, MA) at 1:1000 dilutions for overnight at $4{ }^{\circ} \mathrm{C}$. Racl protein level was detected by goat polyclonal anti-mouse horseradish peroxidase-conjugated secondary antibodies (Beyotime, Jiangsu, China) for $2 \mathrm{~h}$ at room temperature. Protein bands were detected on FluorChem FC2 Imaging System(Alpha Innotech, San Leandro, CA).

Statistical analysis. Statistical analyses were performed using SPSS 16.0 software package ((SPSS Inc., Chicago, IL, USA). All graphs were made using Microsoft Office Excel 2010 software (Microsoft Corporation, Redmond, WA, USA). All data from three independent experiments were expressed as mean \pm SD. Differences were assessed by two-tailed Student's $t$ test. The relationship between RAC1and MEG3 expressions was tested with two-tailed Pearson's correlation. $\mathrm{P}<0.05$ was considered statistically significant.

\section{Results}

LncRNA expression in papillary thyroid cancer and matched lymph node metastatic tissues. Expression profiles of five lnc-RNAs (MEG3, HULC, HOTAIR, NEAT1, and
MALAT-1) previously shown to be involved in cancer metastasis (18) were detected by qRT-PCR in 5 pairs of papillary thyroid cancer and 11 matched lymph node metastatic tissues. Among the five, MEG3 showed significant down-expression in group of metastatic tissues versus matched group of nonmetastatic tissues (Figure 1) $(\mathrm{p}<0.05)$, suggestive of the fact that loss of MEG3 expression may play an important role in papillary thyroid carcinoma development and metastasis.

Overexpression of MEG3 inhibits thyroid cancer cell migration and invasion. Based on the above results, we checked whether MEG3 played the role in modulating migration and invasion of thyroid cancer cells. We infected TPC-1 and HTH83 cells with MEG3-MSCV virus or negative control (NC), and then evaluated by cell invasion and migration assays. As expected, infection of MEG3-MSCV virus increased MEG3 expression compared with negative control in TPC-1 and HTH83 cells (Fig. 2a). Moreover, the cell migration and invasion assay showed that MEG3 over-expression resulted in reduced migration rate and invasion rate both in TPC- 1 and HTH83 cells compared with the control (Fig. 2b). Our results indicate that MEG3 worked as a tumor suppressor miRNA and contributed to inhibition of migration and invasion of thyroid cancer cells.

MEG3 negatively regulates Rac1 gene expression. Long noncoding RNAs are known to modulate hundreds of mRNA targets, resulting in global changes in the cellular phenotype of cells. First, we make an effort to identify potential targets for MEG3 by nucleotide blast in http://blast.ncbi.nlm.nih.gov/ 
A

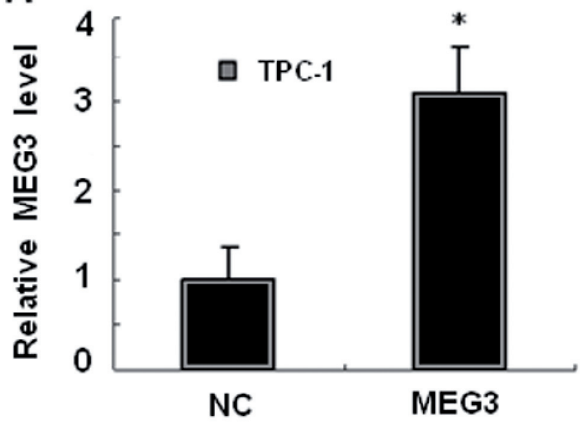

B

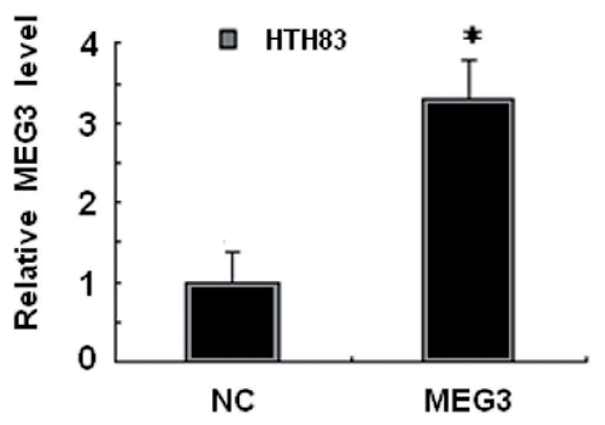

C

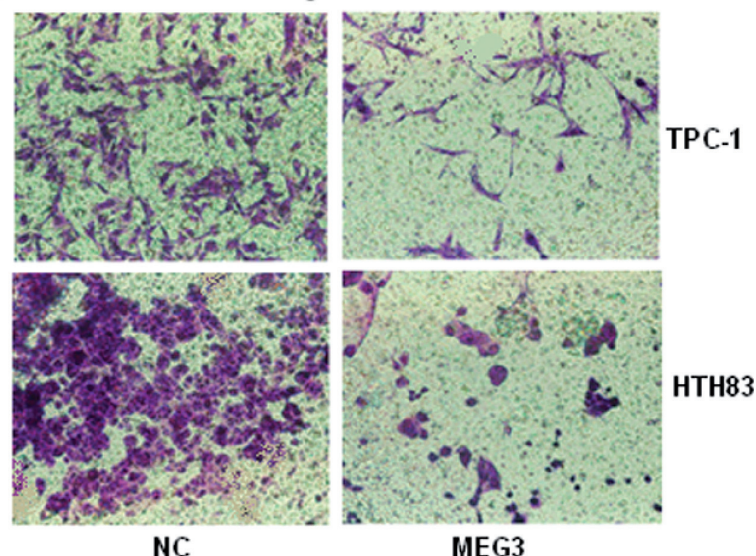

NC

Migration

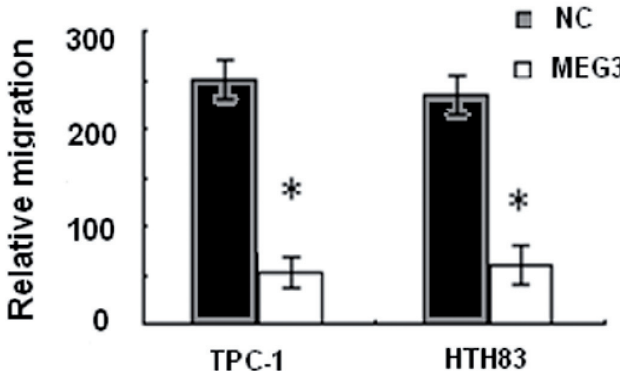

D

Invasion
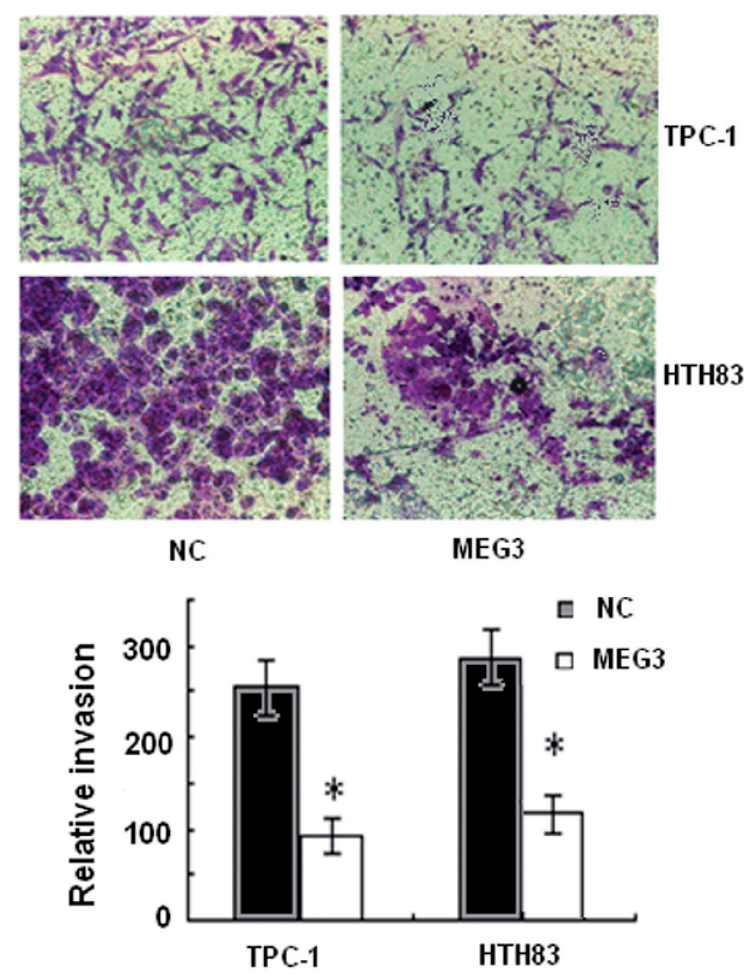

Figure 2. Overexpression of MEG3 inhibits migration and invasion of thyroid cancer cell lines. A, B Infection of MEG3-MSCV virus to TPC-1 and HTH83 increases the expression of MEG3 detected by qRT-PCR. C, D The inhibitory effect of MEG3 toward the invasion and migration of TPC-1 and HTH83 cells. Data are presented as mean \pm SD. Two-tailed Student's $t$ test was used to analyze the significant differences, ${ }^{*} p<0.05$. 
Blast.cgi?CMD=Web\&PAGE_TYPE=BlastHome. We found 3 'UTR of Rac1 as the putative target gene for MEG3 which mediates cell migration and invasion. Further to confirm that Rac1 is a target gene for MEG3, RT-PCR and Western blot analysis were used to detect the expression of Rac1 regulated by MEG3 both in TPC-1 and HTH83 cells. The expression of Rac1 was significantly downregulated at the mRNA (Fig. 3a) and protein level (Fig. 3b) after overexpression of MEG3 compared with negative control. Furthermore, we also detected the mRNA levels of MEG3 and Rac1 in papillary thyroid carcinoma and adjacent normal thyroid tissues by using qRT-PCR. We further assessed the inverse correlation of the MEG3 and Rac1 in papillary thyroid carcinoma. We determined the Racl mRNA and
MEG3 expressions in the same papillary thyroid carcinoma specimens by qRT-PCR. As shown in Fig. 3c, when the Rac1 mRNA levels were plotted against MEG3 expression, a significant inverse correlation was obtained (two-tailed Pearson's correlation analysis, $r=-0.750 ; \mathrm{p}<0.05$ ). Similarly, as shown in Fig. 3d, a significant inverse correlation was also obtained in papillary thyroid carcinoma specimens with lymph-node metastasis (two-tailed Pearson's correlation analysis, $\mathrm{r}=-0.820$; $\mathrm{p}<0.05)$. Taken together, our results suggest that MEG3 negatively regulates Racl gene expression at transcription level, and Rac1 is a potential target gene of MEG3.

Rac1 is a direct target of MEG3. To verify whether MEG3 directly targeted Rac1, Duel luciferase reporter assays were
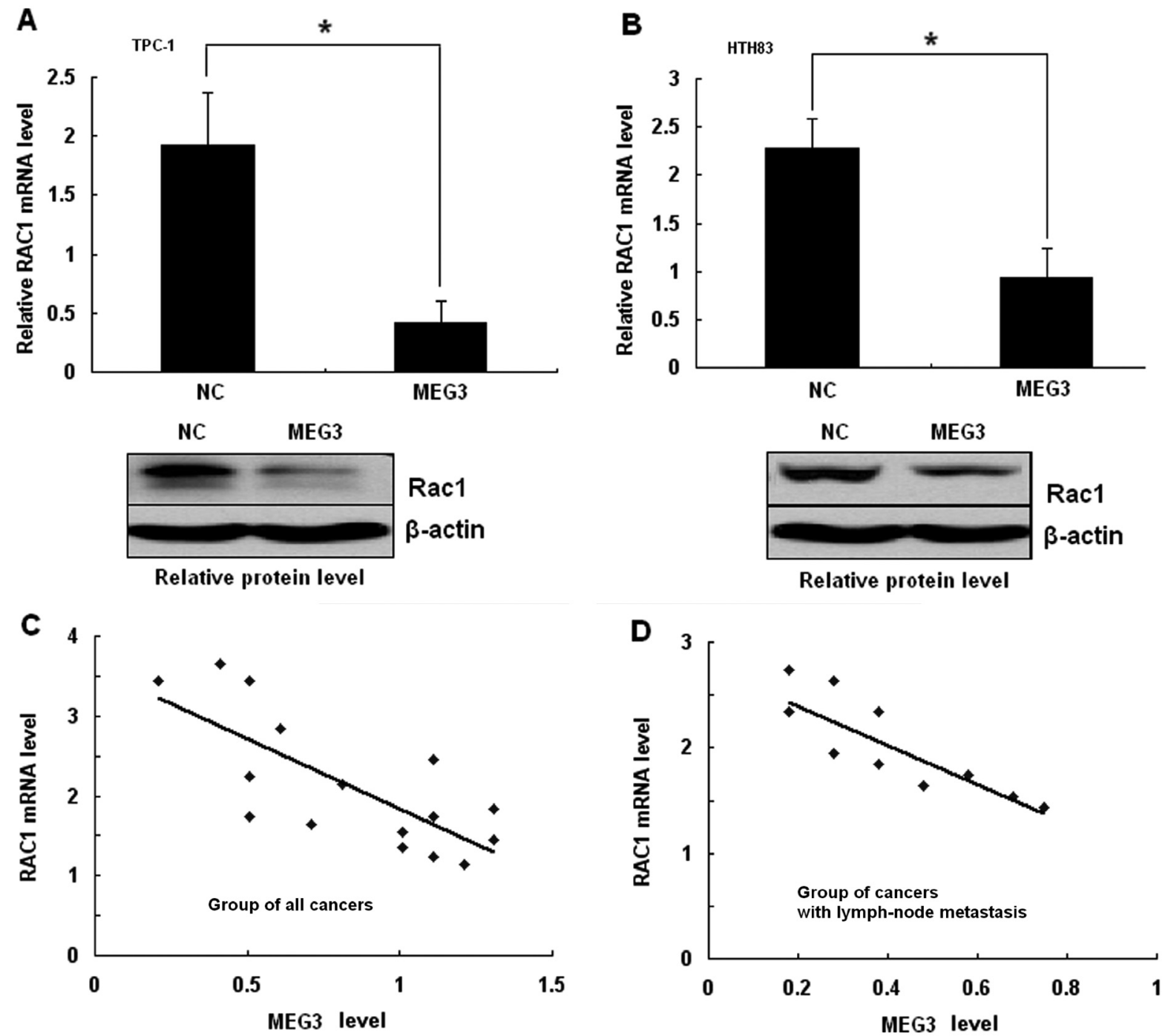

Figure 3. MEG3 negatively regulates Rac1 gene expression. A, B MEG3 inhibited the expression of Rac1 at the mRNA level and the protein level in both TPC-1 (A) and HTH83 (B). Data are presented as mean \pm SD. Two-tailed Student's $t$ test was used to analyze the significant differences, ${ }^{\star}$ p $<0.05$. C, $\mathrm{D}$ Analysis of correlation of MEG3 and Rac1 expression in all papillary thyroid carcinoma tissues $(\mathrm{C}$, two-tailed Pearson's correlation analysis, $\mathrm{r}=0.780$, $\mathrm{p}<0.05, \mathrm{n}=16)$ and papillary thyroid carcinoma tissues with lymph-node metastasis $(\mathrm{D}$, two-tailed Pearson's correlation analysis, $\mathrm{r}=0.860, \mathrm{p}<0.05$, $n=11)$ by detecting the mRNA expression. 
conducted. As shown in Fig. 4, Co-transfection of 293T cells with Rac1-3'UTR/pGL3-BS and MEG3 mimics caused significant decrease in the luciferase activity compared with the negative control $(\mathrm{p}<0.05)$. This repressive effect was disappeared by point mutations in the core binding sites of the Rac1 3'-UTR. This result indicated that MEG3 exerts inhibitory effects on Racl expression via interaction with the 3'UTR of Racl.

Knockdown of Rac1 reduces migration and invasion potential of thyroid cancer cells. To confirm the effects of Rac1 on the migration and invasion of papillary thyroid carcinoma cells, Rac1 expression was knocked down by a Rac1 shRNA. The mRNA and protein expression of Racl was significantly downregulated in TPC-1 and HTH83 cells after Rac1 shRNA treatment (Fig. 5a, b). Consistently, the knockdown of Rac1 strongly reduced cell migration and invasion in TPC-1 and HTH83 cells, which resembled the inhibitory effects of MEG3(Fig. 5c, d). These data suggest that knockdown of Rac1 suppresses migration and invasion in papillary thyroid carcinoma cells and Rac1 is an effective target gene of MEG3.

\section{Discussion}

LncRNAs are more than 200 bps nucleotide non-coding RNAs, it is not necessarily conserved among different species. Long noncoding RNAs are known to modulate hundreds of mRNA targets, resulting in global changes in the cellular phenotype of cells. By regulating protein production transcriptionally, many miRNAs act as oncogenes or tumor suppressor genes. However, the regulation of MEG3 and its precise mechanisms of action in thyroid cancers are not known.

Our data showed that MEG3 was lower expressed in metastasis tissues of papillary thyroid carcinoma than in matched non-matastasis thyroid cancer tissues. We also indicated that MEG3-inhibited two thyroid cancer cells invasion and migration. Taken together, our results suggest that MEG3 as a novel tumor suppressor plays a role in the metastasis and infiltration of papillary thyroid carcinoma. Next, we found Racl is potential target of MEG3 by theoretical prediction. Rac1 is one of the most studied Rho GTPase (19). It contributes to cell proliferation, participates in the signaling pathway promoting

A

Color key for alignment scores

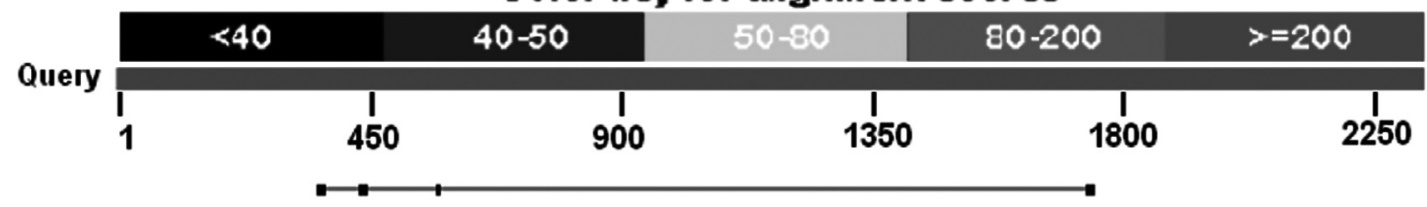

Sequence ID: Ic\|41283 Length: 3768 Number of Matches: 4

\begin{tabular}{|c|c|c|c|c|}
\hline $\begin{array}{l}\text { Score } \\
24.7 \text { bits(26) }\end{array}$ & $\begin{array}{l}\text { Expect } \\
0.31\end{array}$ & $\begin{array}{l}\text { Identities } \\
16 / 18(89 \%)\end{array}$ & $\begin{array}{l}\text { Gaps } \\
0 / 18(0 \%)\end{array}$ & $\begin{array}{l}\text { Strand } \\
\text { Plus/Minus }\end{array}$ \\
\hline
\end{tabular}

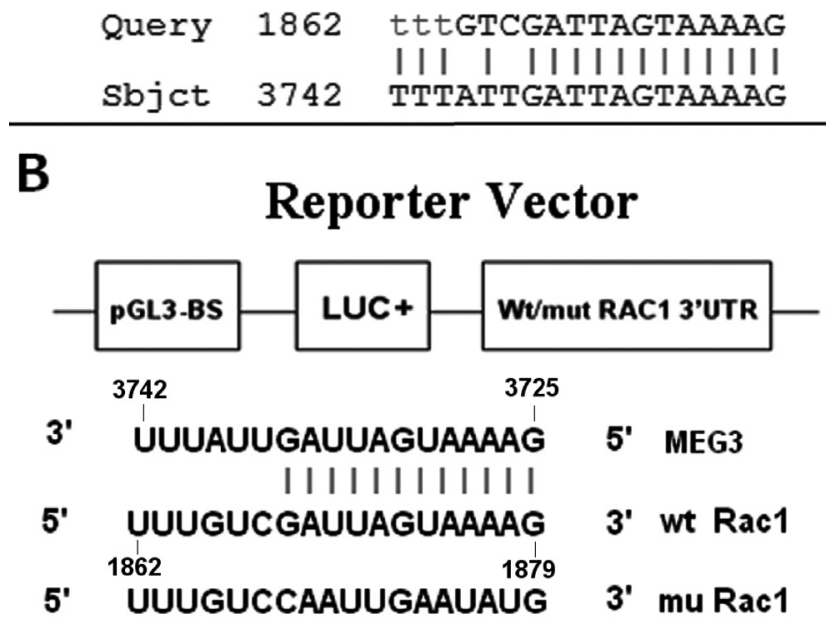

1879 Rac1

3725 MEG3

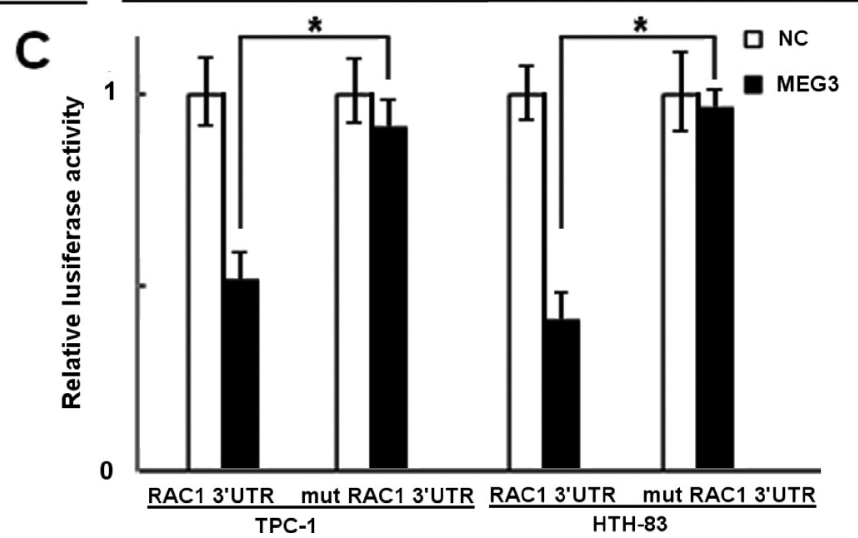

Figure 4. Rac1 3'UTR is a target of MEG3. A Rac1 was the target gene of MEG3 by blast.ncbi.nlm.nih.gov prediction. B Diagram of the luciferase reporter plasmids with the wild-type or mutant Rac1 3 'UTR. C The relative luciferase activity in TPC-1 and HTH83 cells was determined after the plasmid with wild-type or mutant Rac1 3 'UTR was co-transfected with MEG3 mimics. Data are presented as mean \pm SD. Two-tailed Student's $t$ test was used to analyze the significant differences, ${ }^{*} \mathrm{p}<0.05$. 
A

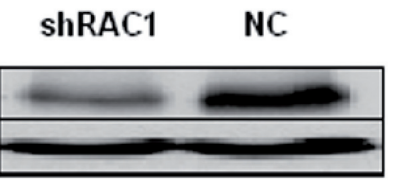

RAC1

TPC-1

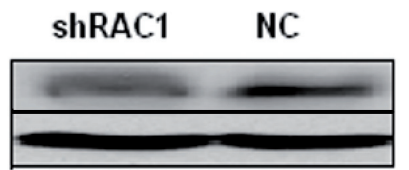

RAC1

HTH83
B

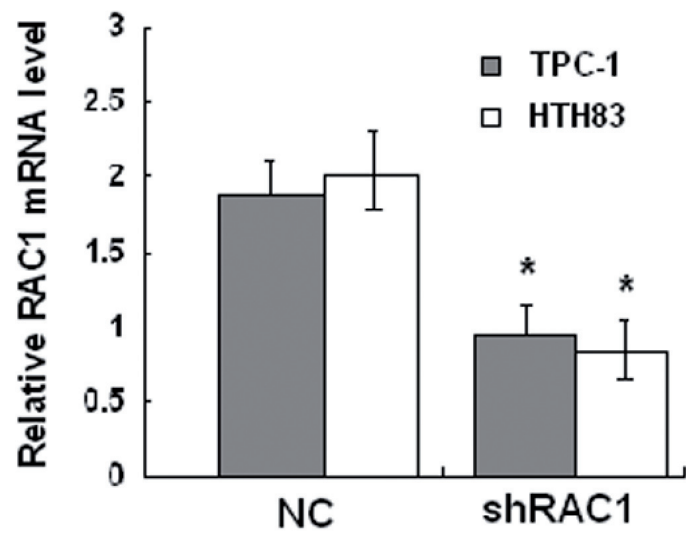

C
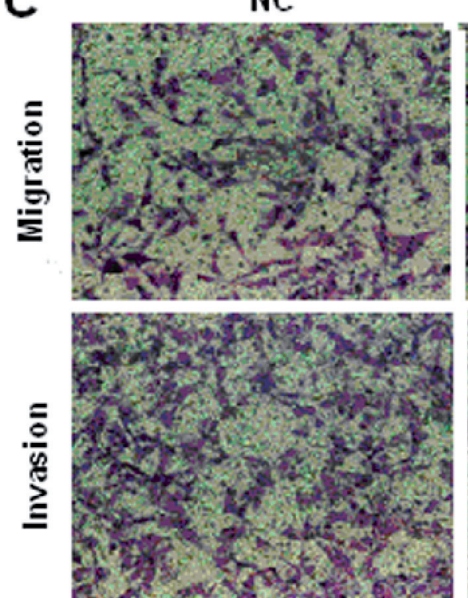

TPC-1

D
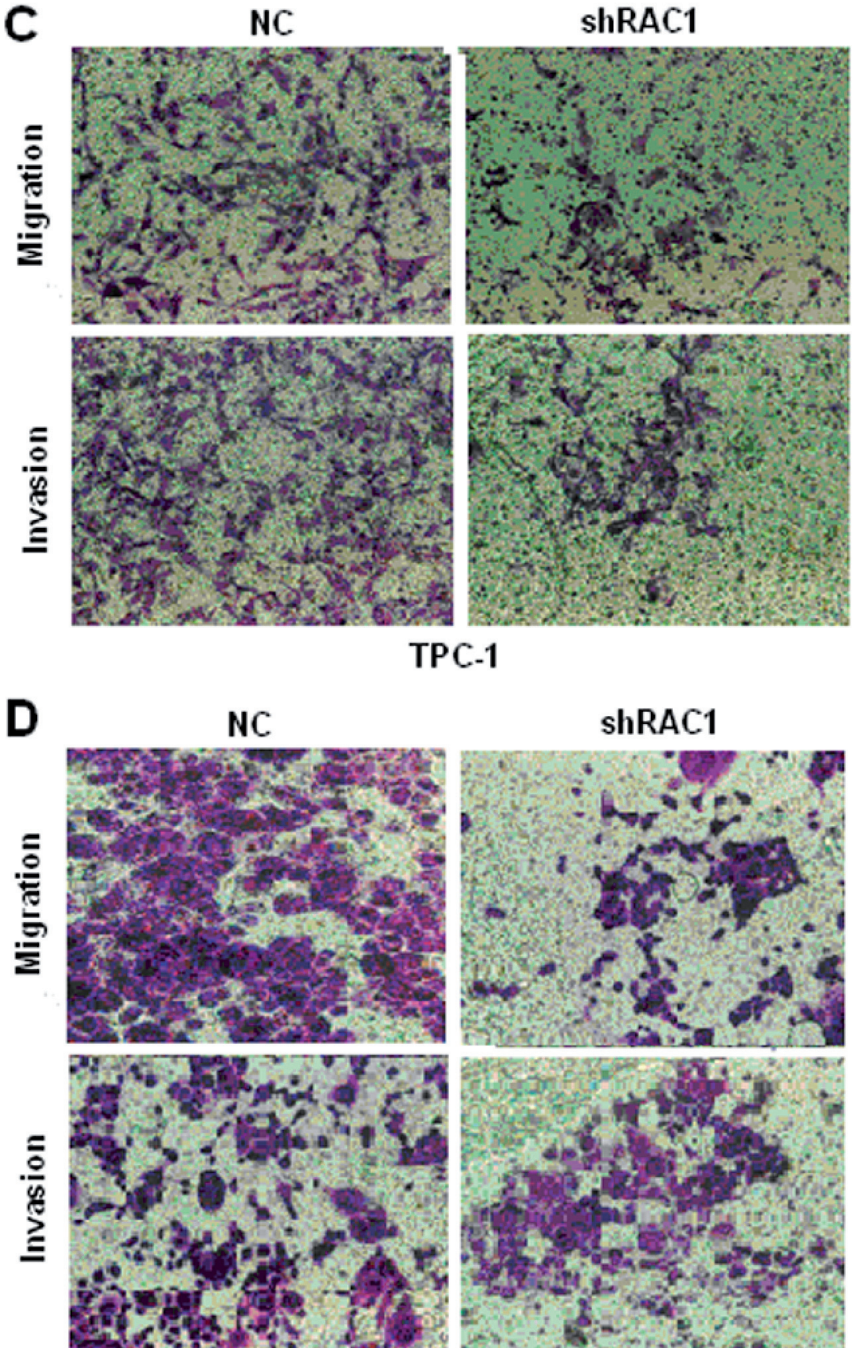

C-1

ShRAC1

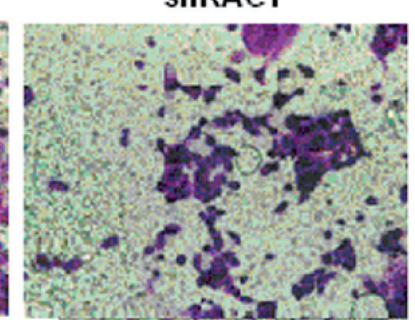

HTH83
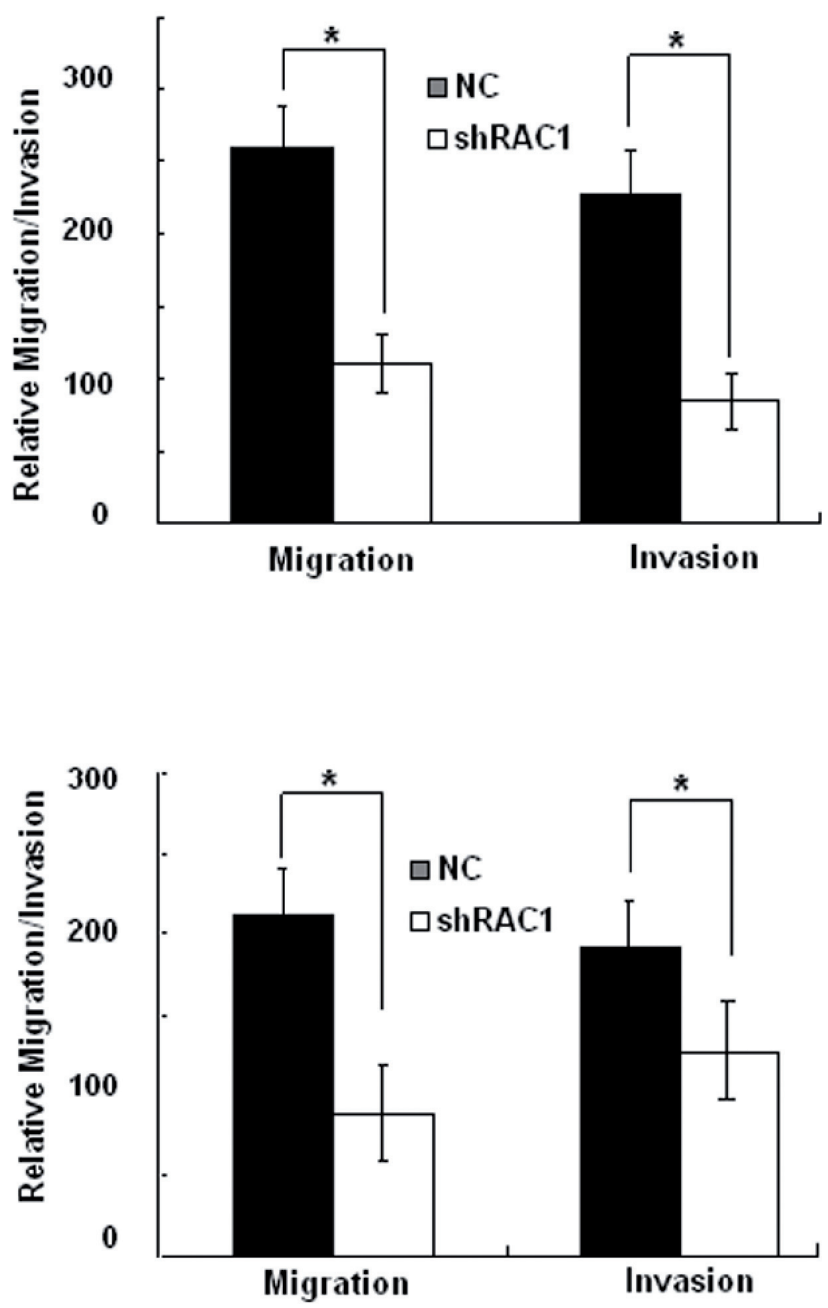

Figure 5. Knockdown of Rac1 reduces migration and invasion in TPC-1 and HTH83 cells. A, B Infection of Rac1 shRNA-MSCV virus inhibited the mRNA and protein expression of Rac1 in both TPC-1 and HTH83 cells. C, D Knockdown of Rac1 by shRNA-inhibited migration and invasion in both TPC-1 and HTH83 cells. Data are presented as mean \pm SD. Two-tailed Student's $t$ test was used to analyze the significant differences, ${ }^{*} p<0.05$. 
cell survival and is known for its central role in the control of cell adhesion and cell migration (20-21).

It has been reported that Rac1 is over-expressed in colorectal and lung tumor (22-23) and related to metastasis and invasion in breast, upper urinary tract, and oral squamous cell tumor(24-27).

Even through Three different microRNAs pathways are related to the molecular mechanism of knockdown of Rac1inhibited migration and invasion (28-30), mechanisms of long noncoding RNAs in thyroid cancers are still not clear. Our study demonstrated that an inverse correlation between MEG3 and Racl expression in the papillary thyroid carcinoma tissues. Our results showed firstly that Racl was negatively regulated by MEG3 at the posttranscriptional level, via a specific target site within the 3'UTR, and MEG3-inhibited thyroid cells migration and invasion through the Racl pathway. Taken together, our results suggest that elevated Rac1, induced by suppressed MEG3 participates in progression of papillary thyroid carcinoma.

Metastasis is the movement or spreading of cancer cells from one organ or tissue to another. Its sequential events include detachment, migration, local invasion, formation of tumor embolus, extravasations, and plant in different organs (31). Some long noncoding RNAs can regulate signal pathway of tumor metastasis (18). The identification of MEG3 as an important regulator of tumor cell migration and invasion in vitro emphasizes an essential role of this lnc-RNA in mediating papillary thyroid carcinoma oncogenesis and tumor behavior.

In summary, our results demonstrate that MEG3 is downregulated in papillary thyroid carcinoma; the down-regulated MEG3 was significantly associated with lymph-node metastasis. Furthermore, MEG3 inhibits invasion and migration in thyroid cancer cells, MEG3 directly inhibited Rac1 expression by targeting its 3 'UTR. In addition, Racl was down-regulated and inversely correlated with MEG3 levels in thyroid carcinoma. Our data suggest that MEG3 is an important tumor suppressor in thyroid carcinoma. The research could lead to new therapies for preventing thyroid cancer metastasis.

Acknowledgements: This work was supported by China National Science Foundation (Grant No. 81273214), the Jiangsu Higher Education Science Foundation (Grant No. 320007), and Jiangsu province university graduate student innovation fund (Grant No. KYLX_1365, CXLX-1439).

\section{References}

[1] FERLAY J, SHIN HR, BRAY F, FORMAN D, MATHERS, et al. Estimates of worldwide burden of cancer in 2008: GLOBOCAN. International journal of cancer 2008; 127: 2893-2917. http://dx.doi.org/10.1002/ijc.25516

[2] QIAN BY, HEM M, DONG SF, WANG JF, CHEN KX Incidence and mortality of thyroid cancers in Tianjin from 1981 to 2001. Chin JEndocrinolM etab 2005; 21: 432-434.
[3] PERRI F, LORENZO G.D, SCARPATI GD, BUONERBA C Anaplastic thyroid carcinoma: A comprehensive review of current and future therapeutic options. World journal of clinical oncology 2011; 2: 150-157. http://dx.doi.org/10.5306/wico.v2.i3.150

[4] MALONE CD, HANNON GJ Small RNAs as guardians of the genome. Cell 209; 136: 656-668.

[5] MOAZED D. Small RNAs in transcriptional gene silencing and genome defence. Nature 2009; 457: 413-420. http://dx.doi. org/10.1038/nature07756

[6] BROSNAN CA, VOINNET O. The long and the short of noncoding RNAs. Curr. Opin. Cell Biol 2009; 21: 416-425. http://dx.doi.org/10.1016/j.ceb.2009.04.001

[7] MATTICK JS. Non-coding RNAs: the architects of eukaryotic complexity. EMBO Reports 2001; 2: 986-991. http://dx.doi. org/10.1093/embo-reports/kve230

[8] KOBAYSSHI S, WAGATSUMA H, ONO R, ICHIKAWA H, Yamazaki M et al. Mouse Peg9/Dlk1 and human PEG9/DLK1 are paternally expressed imprinted genes closely located to the maternally expressed imprinted genes: mouse Meg3/Gtl2 and human MEG3.Genes Cells. 2000; 5: 1029-37. http://dx.doi. org/10.1046/j.1365-2443.2000.00390.x

[9] YAN J, GUO X, XIA J, SHAN T,GU C et al. MiR-148a regulates MEG3 in gastric cancer by targeting DNA methyltransferase 1.Med Oncol. 2014; 31(3): 879. http://dx.doi.org/10.1007/ s12032-014-0879-6

[10] JIA LF, WEI SB, GAO Y, GAN YH,GONG K et al. Expression, regulation and roles of miR-26a and MEG3 in tongue squamous cell carcinoma. Int J Cancer. 2013 Dec 16. http:// dx.doi.org/10.1002/ijc.28667

[11] RIBARSKA T, GOERING W, DROOP J, BASTIAN KM, INGENWERTH $\mathrm{M}$ et al. Deregulation of an imprinted gene network in prostate cancer.BMC Cancer. 2013 7;13:461.

[12] LU KH, LI W, LIU XH, SUN M, ZHANG ML et al. Long non-coding RNA MEG3 inhibits NSCLC cells proliferation and induces apoptosis by affecting p53 expression. Tumour Biol. 2014; 35: 1065-73.

[13] YING L, HUANG Y, CHEN H, WANG Y, XIA L et al. Downregulated MEG3 activates autophagy and increases cell proliferation in bladder cancer. Mol Biosyst. 2013; 9: 407-411. http://dx.doi.org/10.1039/c2mb25386k

[14] BALIK V, SROVNAL J, SULLA I, KALITA O, FOLTANOVA T, et al. MEG3: a novel long noncoding potentially tumoursuppressing RNA in meningiomas. J.Neurooncol. 2013; 112: 1-8 http://dx.doi.org/10.1007/s11060-012-1038-6

[15] WANG P, REN Z, SUN PANG P Overexpression of the long non-coding RNA MEG3 impairs in vitro glioma cell proliferation. J Cell Biochem. 2012 Jun; 113: 1868-74. http://dx.doi. org/10.1002/jcb.24055

[16] W. ZHAO, Y. AN, Y. LIANG, X.W. XIE Role of HOTAIR long noncoding RNA in metastatic progression of lung cancer. European Review for Medical and Pharmacological Sciences. 2014; 18: 1930-1936.

[17] ZHANG J, SOCOLOVSKY M,GROSS A, LODISH HF Role of Ras signaling in erythroid differentiation of mouse fetal liver cells: functional analysis by a flow cytometry-based novel culture system. Blood 102: 3938-3946, 2003. http://dx.doi. org/10.1182/blood-2003-05-1479 
[18] GUTSCHNER T, DIEDERICHS S The Hallmarks of Cancer. a long non-coding RNA point of view. RNA Biol 2012; 9: 703-719. http://dx.doi.org/10.4161/rna.20481

[19] DIDSBURY J, WEBER RF, BOKOCH GM, EVANS T, SNYDERMAN R RAC, a novel ras-related family of proteins that are botulinum toxin substrates. J Biol Chem 1989; 264: 16378-16382.

[20] DEL POZO MA, PRICE LS, ALDERSON NB,REN XD SCHWARTZ MA Adhesion to the extracellular matrix regulates the coupling of the small GTPase Rac to its effector PAK. EMBO J 2000; 19: 2008-2014. http://dx.doi.org/10.1093/ emboj/19.9.2008

[21] CHUNG CY, LEE S, BRISCOE C, ELLSWORTH C, FIRTEL RA Role of Rac in controlling the actin cytoskeleton and chemotaxis in motile cells. Proc Natl Acad Sci USA 2000; 97: 5225-5230. http://dx.doi.org/10.1073/pnas.97.10.5225

[22] ZHAO SY, SUN Y, LAI ZS,NAN QZ, LI K, et al. Inhibition of migration and invasion of colorectal cancer cells via deletion of Rac1 with RNA interference. Mol Cell Biochem 2009; 322: 179-84. http://dx.doi.org/10.1007/s11010-008-9955-6

[23] CHEN QY,XU LQ, JIAO DM, YAO QH, WANG YY, et al. Silencing of Rac1 modifies lung cancer cell migration, invasion and actin cytoskeleton rearrangements and enhances chemosensitivity to antitumor drugs. Int J Mol Med 2011; 24: 769-76.

[24] ZHEN C, CHEN L, ZHAO Q, LIANG B, GU YX, et al. Gankyrin promotes breast cancer cell metastasis by regulating Racl activity. Oncogene 2013; 32: 3452-60. http://dx.doi. org/10.1038/onc.2012.356

[25] HERNANDEZ E, DE LA MOTA-PEYNADO A, DHARMAWARDHANE S, Vlaar CP Novel inhibitors of Rac1 in metastatic breast cancer. P R Health Sci J 2010; 29: 348-56.

[26] KAMAI T, SHIRATAKI H, NAKANISHI K,FURUYA N, KAMBARA T, et al. Increased Racl activity and Pak1 overexpression are associated with lymphovascular invasion and lymph node metastasis of upper urinary tract cancer. BMC Cancer 2010; 10: 164. http://dx.doi.org/10.1186/1471-240710-164

[27] YAP LF, JENEI V, ROBINSON CM,MOUTASIM K,BENN $\mathrm{TM}$, et al. Upregulation of Eps8 in oral squamous cell carcinoma promotes cell migration and invasion through integrin-dependent Rac1 activation. Oncogene 2009; 28: 2524-34. http://dx.doi.org/10.1038/onc.2009.105

[28] WANG P, CHEN L, ZHANG J, CHEN H,FAN J, et al. Methylation-mediated silencing of the miR-124 genes facilitates pancreatic cancer progression and metastasis by targeting Rac1. Oncogene 2013; 21. http://dx.doi.org/10.1038/ onc.2012.598

[29] IMAM JS, PLYLER JR, BANSAL H,PRAJAPATI S, BANSAL S, et al. Genomic loss of tumor suppressor miRNA-204 promotes cancer cell migration and invasion by activating $\mathrm{AKT} / \mathrm{mTOR} / \mathrm{Rac} 1$ signaling and actin reorganization. PLoS One 2012; 7: e52397. http://dx.doi.org/10.1371/journal. pone.0052397

[30] Zhou Y, Su J, Shi L, Liao Q, SU Q DADS downregulates the Rac1-ROCK1/PAK1-LIMK1-ADF/cofilin signaling pathway, inhibiting cell migration and invasion. Oncol Rep 2013, 29: 605-12.

[31] GUPTA GP, MASSAGUE J Cancer metastasis: building a framework. Cell 2006; 127: 679-695. http://dx.doi. org/10.1016/j.cell.2006.11.001 